\title{
Antimicrobial activity of Caribbean sponge extracts
}

\author{
Rochelle W. Newbold ${ }^{1}$, Paul R. Jensen ${ }^{2}$, William Fenical ${ }^{2}$, Joseph R. Pawlik ${ }^{1, *}$ \\ 'Biological Sciences and Center for Marine Science Research, University of North Carolina at Wilmington, Wilmington, \\ North Carolina 28403-3297, USA \\ ${ }^{2}$ Scripps Institution of Oceanography, Center for Marine Biotechnology and Biomedicine, University of California, \\ San Diego, La Jolla, California 92093-0236, USA
}

\begin{abstract}
Marine sponges produce a diversity of unusual chemical compounds, but the ecological functions of these metabolites remain largely unknown. To determine if sponge secondary metabolites have ecologically significant antimicrobial effects, organic extracts from 33 species of Caribbean sponges were assayed for antibiotic activity against a test panel of marine bacteria. The test panel consisted of 8 strains representing 6 genera of marine bacteria and included an opportunistic pathogen (Vibrio parahaemolyticus), a common fouling bacterium (Deleya marina), and strains isolated from seawater and healthy and necrotic Caribbean sponges. Extracts were tested for antibiotic activity at concentrations that were volumetrically equivalent to those found in sponge tissues (whole-tissue concentrations). Bioassay results revealed that 16 species $(48 \%)$ exhibited antibiotic activity against at least 1 bacterial isolate and that the 2 bacteria isolated from necrotic sponge tissues were the most sensitive test strains (inhibited by $40 \%$ of the extracts). Extracts from Amphimedon compressa, Amphimedon erina, Aplysina lacunosa, and Ptilocaulis spiculifera inhibited the largest numbers of test strains and exhibited the most potent antibiotic activities with values frequently exceeding those of a control antibiotic (gentamicin). The pattern of antimicrobial activity was different for 15 of 16 active sponge species, suggesting that diverse taxa do not produce similar antibacterial metabolites. Overall, only $23 \%$ of the extract/bacterial interactions exhibited antibacterial activity, indicating that, in general, conspicuous members of the Caribbean sponge community do not produce broad-spectrum antibacterial metabolites. All of the species yielding antibacterial extracts also deterred feeding by reef fishes in a previous study, suggesting that some secondary metabolites may have evolved multiple defensive functions. Stevensine, a compound from Axinella corrugata ( $=$ Teichaxinella morchella) known to deter feeding by predatory reef fishes, exhibited weak antimicrobial activity, suggesting that this potent feeding deterrent is not solely responsible for the antimicrobial activity detected in the crude sponge extract.
\end{abstract}

KEY WORDS: Chemical defense $\cdot$ Antimicrobial $\cdot$ Sponges $\cdot$ Secondary metabolites

\section{INTRODUCTION}

Sponges are simple, multicellular, sessile animals with no true tissue layers or organs (Bergquist 1978). They inhabit every type of marine environment, from polar seas (Dayton et al. 1974) to temperate and tropical waters (Reiswig 1973, Wenner et al. 1983), and are often more abundant and diverse in the tropics than stony and soft corals (Targett \& Schmahl 1984). Sponges feed on bacteria (Bergquist 1978) and are

\footnotetext{
•Addressee for correspondence.E-mail: pawlikj@uncwil.edu
}

constantly exposed to large populations of water-borne microbes, including opportunistic pathogens and fouling microorganisms. Despite these constant threats and a lack of the complex morphological and cellular defense mechanisms used by higher animals to combat bacterial pathogenesis (Simpson 1968, Zhuravleva 1970), sponges are highly successful members of the benthos and suffer few obvious bacterial infections.

The sponge class Demospongiae is known to produce the largest number and diversity of secondary metabolites isolated from marine invertebrates (Faulkner 1998, and references cited therein). Although the functions of these secondary metabolites are largely 
unknown, there is some evidence that they provide chemical defenses against predators (e.g. Pawlik et al. 1995. Chanas et al. 1996). It has also been suggested that sponge secondary metabolites may provide defenses against fouling and infection (Amade \& Chevolot 1982, Thompson et al. 1985, Pawlik 1993); however, this possibility has not been adequately explored.

The first report of antimicrobial activity of sponge extracts was by Nigrelli et al. (1959). Since then, there has been a growing number of antimicrobial extracts reported from marine sponges (Burkholder \& Rützler 1969, Bergquist \& Bedford 1978, Tachibana et al. 1981, Amade \& Chevolot 1982, Amade et al. 1987, Uemera 1991), but these studies have generally used terrestrial microorganisms and human pathogens to assess antimicrobial activity. Some organic extracts from sponges have additionally yielded compounds with pharmacological properties such as antitumor, antifungal, and antiviral activity (Schmitz \& Gopichand 1978, Stonard \& Andersen 1980, Tachibana et al. 1981, Kashman et al. 1989), Despite the wealth of biologically active secondary metabolites isolated from marine sponges, the potential functions of these compounds in antimicrobial chemical defense have rarely been explored (Burkholder \& Rützler 1969, Mokashe et al. 1994).

In this study, we tested the crude organic extracts of 33 species of Caribbean sponges for antibacterial activity against a panel of 8 strains of marine bacteria that included isolates from necrotic and healthy sponges, an opportunistic pathogen, and a fouling bacterium. We sought to answer the following questions: (1) Do sponge organic extracts tested at whole-tissue concentrations inhibit the growth of marine bacteria? (2) Do antibacterial sponge extracts exhibit broadspectrum or selective antibacterial activity? and (3) Do sponge extracts that deterred feeding by reef fishes in a previous study (Pawlik et al. 1995) also exhibit antibacterial activity?

\section{MATERIALS AND METHODS}

Sponge collection. Thirty-three species of marine demosponges were collected from the reef and mangrove areas off the Bahamas and Florida Keys, USA. For each species, replicate samples were collected from 3 locations separated by $>10 \mathrm{~km}$ to avoid collecting asexually produced clones. Sponge samples were collected in the Bahamas from reef and mangrove areas off the islands of Sweetings Cay, Eleuthera, Little San Salvador, Chubb Cay and Andros during June and July 1996 while on board the RV 'Seward Johnson'. Sponges were also collected during May and August 1997 from the reef and mangrove areas off Key Largo, Florida. The sponges were collected at 1 to $27 \mathrm{~m}$ depth by snorkeling and SCUBA. Each sponge sample was immediately frozen after collection and maintained at $-20^{\circ} \mathrm{C}$ prior to extraction.

Bacterial panel. Sponge extracts were tested for antibacterial activity using a panel of 8 strains of marine bacteria (Table 1). Two of these strains, the opportunistic marine pathogen Vibrio parahaemolyticus (ATCC 27969) and the surface fouling bacterium Deleya marina (ATCC 25374), designated VP and DM, respectively, were obtained from the American Type Culture Collection (ATCC, Rockville, MD, USA). The remaining 6 strains were isolated from samples taken in the Bahamas using standard serial dilution and plating techniques on medium B1 $10.25 \%$ peptone, $0.15 \%$ yeast extract, $0.15 \%$ glycerol, $1.6 \%$ agar, $100 \%$ seawater). These strains were tentatively identified by fatty acid methyl ester (FAME) analysis (Microbial ID, Inc., Newark, DE, USA, using the Sherlock Microbial ID System). Two of these strains were isolated from the surface tissues of necrotic reef sponges (NS1 from Ircinia strobilina and NS2 from Agelas clathrodes), 2 from the surface tissues of healthy sponges (HS3 from Chondrilla nucula and HS4 from Pandaros acanthifolium), and 2 from seawater (SW5 and SW6).

Table 1. Source and FAME (fatty acid methyl ester) identification of the 8 bacterial isolates used in disc-diffusion assay. According to Microbial ID, Inc., a similarity index of $>30 \%$ is considered a good match at the genus level. ATCC: American Type Culture Collection. na: not applicable

\begin{tabular}{|llll|}
\hline Strain & Source & Identification & FAME similarity (\%) \\
\hline NS1 & Necrotic reef sponge Ircinia strobilina & Bacillus sp. & 37 \\
NS2 & Necrotic reef sponge Agelas clathrodes & Bacillus sp. & 98 \\
HS3 & Healthy mangrove sponge Chondrilla nucula & Vibrio parahaemolyticus & 93 \\
HS4 & Healthy reef sponge Pandaros acanthifolium & Vibrio alginolyticus & 89 \\
SW5 & Seawater & Listonella anguillarum & 93 \\
SW6 & Seawater & Alcaligenes piechaudii & 51 \\
VP & ATCC & Vibrio parahaemolyticus & na \\
DM & ATCC & Deleya marina & na \\
\end{tabular}


Extraction. Each sponge specimen was allowed to thaw, cut into small pieces, and then added to a graduated cylinder containing $10 \mathrm{ml}$ of $1: 1$ methanol:dichloromethane until a final volume of $20 \mathrm{ml}$ was achieved. This solvent mixture was chosen for the effectiveness with which it extracts a broad polarity range of secondary metabolites. Sponge tissue and solvent were transferred to capped containers and agitated for $24 \mathrm{~h}$. After extraction, the sponge tissue was removed from the container and solvents squeezed from the tissue. The extract was evaporated to dryness under vacuum at room temperature and redissolved in $10 \mathrm{ml}$ of $4: 1 \mathrm{MeOH}: \mathrm{H}_{2} \mathrm{O}$, thereby producing a solution containing the extract at the volumetric concentration of the original tissue.

Antibiotic assays. Assays were performed as previously described (Jensen et al. 1996), with the exception that a 4-salt solution was substituted for seawater (Quigley \& Colwell 1968) in the agar medium. In brief, $25 \mu$ of each sponge extract (whole-tissue concentration) was pipetted onto a sterile paper disc (Difco, Detroit, MI, USA) that had been suspended on top of a dissecting needle. The volume added was chosen because it represents the approximate volumetric capacity of each disc. The solvent was allowed to evaporate and the discs (up to 9 plate $^{-1}$ ) were then placed onto the surface of petri dishes that had previously been surface-inoculated with individual test strains. Plates were then incubated at $24^{\circ} \mathrm{C}$ for $24 \mathrm{~h}$. Solvent control discs were prepared in the same manner and were never observed to inhibit bacterial growth. Gentamicin discs, treated with $10 \mathrm{mg} \mathrm{disc}^{-1}$ of gentamicin (Difco), were used as antibiotic standards on each plate. Three replicate sponge extracts, each from a sample of the same species of sponge collected from geographically distant locations, were assayed on different plates.

Assays were also performed on the purified sponge compound stevensine, a fish feeding deterrent isolated from Axinella corrugata (Albizati \& Faulkner 1985, Wilson et al. in press). Assay discs were treated with $25 \mu \mathrm{l}$ of stevensine in 1:4 MeOH: $\mathrm{H}_{2} \mathrm{O}$ at the following concentrations: $10,15,25,50,100$ and $200 \mathrm{mg} \mathrm{ml}^{-1}$.

After incubation, the radius of each disc, plus any clear zone surrounding the disc, was measured to the nearest $\mathrm{mm}$. A sponge was considered active if one or more replicate extracts (each from a different sponge sample of the same species, but from different locations) produced a zone of inhibited bacterial growth $\geq 1 \mathrm{~mm}$ beyond the edge of the disc (radius $=3 \mathrm{~mm}$ ). The area of this zone of inhibition was calculated for each replicate assay of discs treated with sponge extracts, and for gentamicin discs, and mean and standard deviations calculated for all treatments. Because the disk-diffusion assay is used to assess qualitative differences in antimicrobial activity, and is not without limitations (Jensen et al. 1996, Jenkins et al. 1998), statistical analyses were not used to assign significance between treatments.

\section{RESULTS}

Assays of extracts of 33 sponge species revealed considerable variability in antibacterial activity, with $48 \%(16 / 33)$ of the sponge species inhibiting at least 1 bacterial isolate (Fig. 1). Extracts of the following 16 sponge species were inactive against all of the bacterial isolates: Aplysina cauliformis, Callyspongia vaginalis, Chondrilla nucula, Chondrosia collectrix, Ectyoplasia ferox, Geodia gibberosa, Geodia neptuni, Iotrochota birotulata, Lissodendoryx sigmata, Mycale laxissima, Myrmekioderma styx, Niphates digitalis, Niphates erecta, Pandaros acanthifolium, Pseudaxinella lunaecharta, Pseudoceratina crassa, and Tedania ignis. In total, $23 \%(62 / 264)$ of the extract/bacteria interactions resulted in inhibited bacterial growth. Of the 8 test strains, NS1 was the most sensitive (inhibited by $39 \%$ of the sponge species), followed by NS2 and HS4 (36\%), SW5 (21\%), DM and VP (18\%), HS3 $(12 \%)$, and SW6 (9\%). With the exception of HS4 (Vibrio alginolyticus), the 2 most sensitive test strains were both Bacillus spp. isolated from necrotic sponges (See FAME identities in Table 1). Despite the fact that HS3 and VP were both identified as Vibrio parahaemolyticus (Table 1), VP was inhibited by 2 more sponge extracts than HS3, and VP was inhibited by gentimicin, while HS3 was not.

Grouping the test bacteria by source, necrotic sponge isolates (NS1 and NS2) were sensitive to $38 \%$ of the extracts, healthy sponge isolates (HS3 and HS4) were sensitive to $24 \%$ of the extracts, the opportunistic pathogen and fouling strain (DM and VP) were sensitive to $18 \%$ of the extracts, and the seawater isolates (SW5 and SW6) were sensitive to $14 \%$ of the extracts. If the bacteria are further categorized as spongeassociated and non-sponge-associated, the activity rates are 31 and $16 \%$, respectively. Three isolates (HS3, SW5, SW6) were resistant to gentimicin, but these were inhibited by 4,7 , and 3 sponge extracts, respectively.

Extracts of Amphimedon compressa exhibited antimicrobial activity against all 8 bacterial isolates (Fig. 1). Extracts of Ptilocaulis spiculifera, Aplysina lacunosa, and Amphimedon erina exhibited antimicrobial activity against 7 of 8 isolates, with the first of these yielding the largest zones of inhibition observed in this study. Extracts of Agelas wiedenmeyeri were active against 5 of 8 isolates, and Teichaxinella morchellum and Aplysina fistularis were each active against 4 isolates. Extracts of 4 sponge species were active against 3 


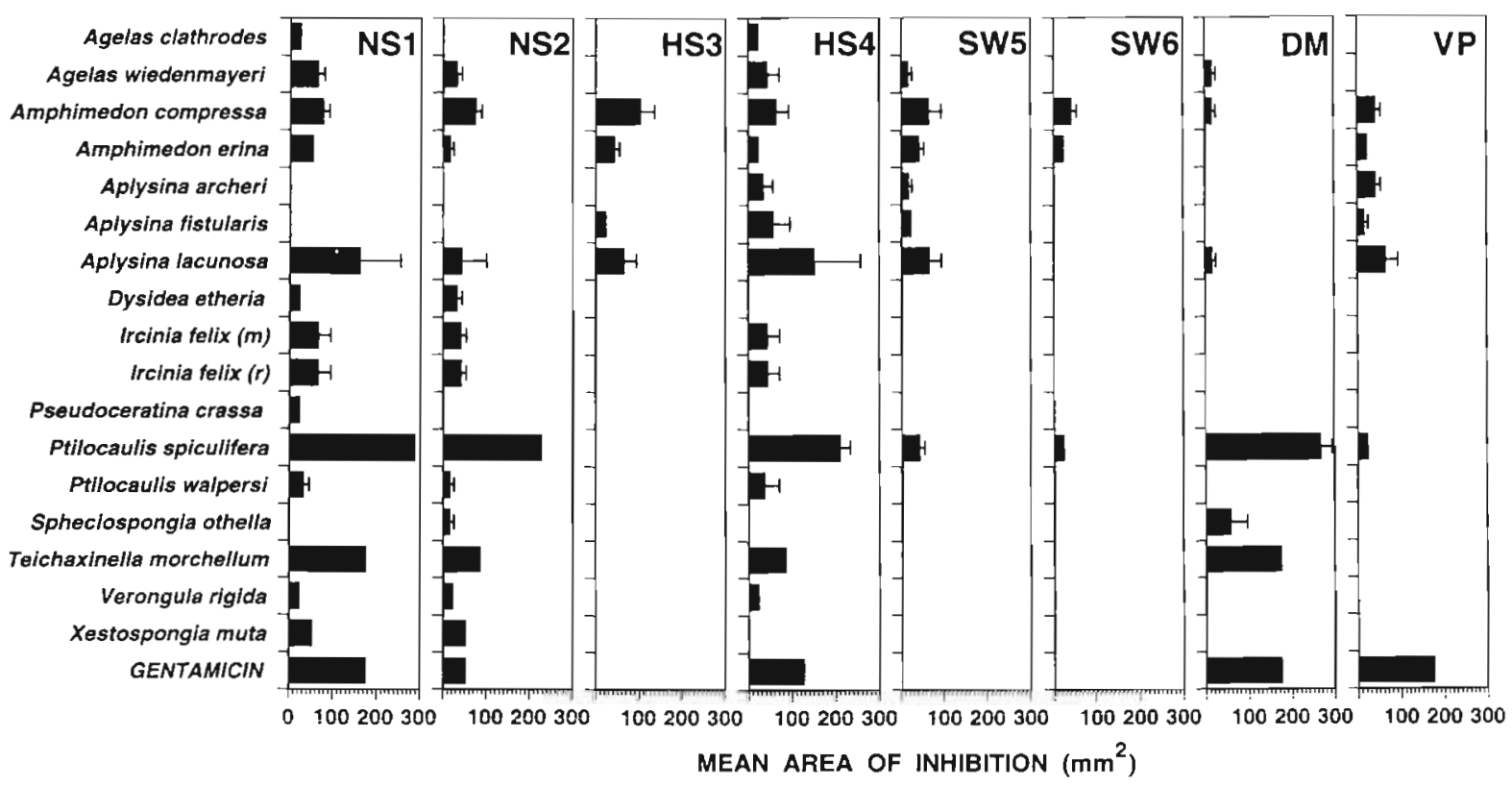

Fig. 1. Disc-diffusion assay. Mean area of growth inhibition of 8 bacterial isolates around assay discs treated with crude organic extracts of 16 sponge species and the antibiotic gentamicin. Mean plus 1 standard deviation is shown for each extract ( $\mathrm{n}=3$ ). NS 1 and NS2: isolated from necrotic reef sponges; HS3 and HS4: isolated from healthy sponges; SW5 and SW6: isolated from seawater; DM: Deleya marina; VP: Vibrio parahaemolyticus. Teichaxinella morchellum has been changed to Axinella corrugata

isolates and an additional 5 species were only active against 1 or 2 bacterial isolates, of which at least one was obtained from a necrotic sponge (NS1 or NS2). The pattern of antimicrobial activity for 15 of the 16 active species was different (i.e. no 2 species generated extracts that were active against the same bacterial isolates).

Ircinia felix has different growth forms in reef and mangrove environments. Extracts of both morphologies exhibited similar levels of activity against the same 3 bacterial isolates (Fig. 1).

The compound stevensine, isolated from Axinella corrugata, exhibited antimicrobial activity at a concentration of 50 to $200 \mathrm{mg} \mathrm{ml}^{-1}$ against NS1, NS2, HS4, and DM. The activity of the purified compound at all concentrations was less than that of the sponge crude extract for all sensitive strains except for stevensine at $200 \mathrm{mg} \mathrm{ml}^{-1}$ against NS2, which exhibited the same activity as the crude extract of $A$. corrugata.

\section{DISCUSSION}

Sponges have few obvious defenses, yet for most species survival is dependent on their ability to deter predators, inhibit pathogenic microbes, and discourage the formation of a bacterial biofilm and subsequent macrofouling community. Research has indicated that sponge secondary metabolites may play important roles as defenses against some of these biotic challenges (Burkholder \& Rützler 1969, Amade \& Chevolot 1982, Thompson et al. 1985, Amade et al. 1987, Pawlik et al. 1995, Chanas et al. 1996); however, with the possible exception of predator deterrence, our understanding of sponge chemical ecology is poorly developed. The present study was an attempt to determine the extent to which diverse Caribbean sponge taxa produce metabolites that inhibit the growth of $\mathrm{co}$ occurring and potentially deleterious marine bacteria and to address the possibility that some of these compounds serve multiple defensive roles.

Previous studies using assay methods similar to those reported here have demonstrated that organic extracts of Mediterranean sponges (Amade \& Chevolot 1982) and Caribbean gorgonian soft corals (Jensen et al. 1996) did not exhibit a high degree of antibacterial activity against marine bacteria. Only 8 of 100 extracts of hard corals exhibited activity against a panel of heterotrophic bacteria, although all 100 inhibited cyanobacterial growth (Koh 1997). We observed that $52 \%$ of the sponge species tested did not inhibit any of the 8 bacterial test strains and that only $23 \%$ of the extract/bacteria interactions resulted in antibiotic activity. These results lead us to conclude that the extracts of Caribbean sponges, in general, do not contain broad-spectrum, antibacterial agents inhibitory to the growth of common, co-occurring and potentially harmful marine bacteria. However, extracts from spe- 
cific taxa, e.g. Amphimedon compressa, Ptilocaulis spiculifera, Aplysina lacunosa, and Amphimedon erina, which inhibited 88 to $100 \%$ of the test strains, may be exceptions to this generalization. Additional species that exhibited selective activity against a few members of the test panel may contain antibacterial agents targeting specific bacterial taxa and, although not characterized as having broad-spectrum activity, these activities may nonetheless represent functional antibacterial chemical defenses. Similar conclusions were reached by Kelman et al. (1998) in their examination of the antimicrobial activity of extracts of developmental stages and adults of the Red Sea soft coral Parerythropodium fulvum fulvum.

It is interesting to note that, as a group, bacteria isolated from sponge tissues (healthy and necrotic) were on average the most sensitive strains (inhibited by $33 \%$ of the sponge extracts). This result suggests that the evolution of secondary metabolites in some sponge taxa may have been influenced by co-occurring bacteria, a concept that clearly warrants further study before any conclusions can be drawn. That the 2 strains isolated from necrotic sponges were both Bacillus spp. suggests that Gram-positive bacteria may represent some previously unrecognized threat against which some sponge taxa may be chemically defended.

Given that the production of secondary metabolites requires energy that might otherwise be allocated to growth or reproduction (Herms \& Mattson 1992), sponges may have evolved secondary metabolites that play multiple defensive roles, i.e. as feeding deterrents and antibacterial agents. For example, it was recently discovered that the secondary metabolites present in some algae may play the dual role of inhibiting herbivory and preventing fouling (Schmitt et al, 1995). In the present study, all of the 16 sponge species whose crude organic extracts exhibited antibacterial activity also inhibited feeding by predatory reef fish in aquarium assays (Pawlik et al. 1995). Five extracts that did not exhibit antibacterial activity were similarly non-deterrent in fish feeding assays. The compound stevensine, which has been identified as the metabolite from Axinella corrugata that deters feeding by predatory reef fish (Wilson et al. in press), also exhibited weak antibacterial activity in the present study. The zones of inhibition produced by crude extracts of $A$. corrugata, however, were greater than those for purified stevensine, and stevensine was minimally active at $50 \mathrm{mg} \mathrm{ml}^{-1}$, while the mean concentration of the compound in the sponge is $19 \mathrm{mg} \mathrm{ml}^{-1}$ (Wilson et al. in press), suggesting that stevensine may not be the only antibacterial secondary metabolite produced by this sponge.

The secondary metabolites present in sponges of the genus Amphimedon may also play multiple defensive roles. Extracts of $A$. compressa and $A$. erina contain complex polymers of pyridinium alkaloids, including halitoxin and amphitoxin (Schmitz \& Gopichand 1978 , Albrizio et al. 1995). In previous studies, these compounds exhibited general cytotoxicity and were toxic to fish and mice (Schmitz \& Gopichand 1978). Amphitoxin also inhibits feeding by reef fishes in aquarium assays (Albrizio et al. 1995). In the present study, extracts of $A$. compressa and $A$. erina exhibited among the broadest and most potent antibacterial activities. While purified compounds from these sponges were not assayed, it is likely that the observed antibacterial activity is the result of the presence of the previously identified and highly bioactive pyridinium alkaloids.

Despite the foregoing, it is clear that not all compounds that deter fish feeding also display antibacterial activity. Extracts from 11 of 33 species of sponges assayed in the present study exhibited no antibiotic activity yet deterred feeding by reef fish (Pawlik et al. 1995). The species in one genus of sponges in particular, Agelas, are potently defended against potential predators from a mixture of brominated pyrrole-containing compounds (Chanas et al. 1996), yet the crude extract of $A$. wiedenmeyeri was only moderately antibacterial. Although some metabolites may act to defend sponges from both microbial attack and from potential predators, available evidence suggests that many sponge chemical defenses have not evolved for both roles.

The antibiotic results presented here were obtained using disc-diffusion assays, the limitations of which have been discussed in detail elsewhere (Jensen et al. 1996, Jenkins et al. 1998). In the present study, extracts were tested at whole-tissue concentrations. Without information about rates of compound release into the surrounding seawater and the localization of metabolites in specific tissues however, it is not possible to determine how the test concentrations compare with those potentially experienced by microbes in nature. It is not unreasonable to assume that whole-tissue concentrations overestimate natural concentrations, and if activities are not detected at these levels, it is unlikely that antibacterial effects occur in nature. Of course it is possible that sponges maintain antibacterial chemical defenses that (1) are induced by microbial challenge, (2) are non-toxic (e.g. induce a negative chemotactic response), (3) target bacteria that were not included in the test panel, or (4) are concentrated in surface tissues and therefore were not detected with the methods used here. The assay results presented herein must also be interpreted with caution as activities are dependent on the rate of compound diffusion in agar, and zone sizes may not accurately reflect in situ potencies.

It is interesting to note that 15 of 16 active sponge species did not inhibit the same strains of bacteria in the test panel (Fig. 1). This result suggests that differ- 
ent species produce different antibacterial metabolites and that, if these metabolites are functioning as antibacterial chemical defenses, it is likely that they target different microbial threats. The 4 species that inhibited the largest numbers of test bacteria ( $\mathrm{Am}$ phimedon compressa, Ptilocaulis spiculifera, Aplysina lacunosa, and Amphimedon erina) generally produced the most potent extracts, justifying further investigation of the hypothesis that select Caribbean sponges maintain antibacterial chemical defenses.

Acknowledgements. This project was conducted by R.W.N. as part of an undergraduate research program at the University of North Carolina at Wilnington (UNCW). Funding was provided by the National Science Foundation, CHE9322776 (to W.F.) and OCE9314145 and OCE9711255 (to J.R.P.), and by the National Sea Grant College Program, National Oceanic and Atmospheric Administration, US Department of Commerce, under grant no. NA89AA-D-SG138, project no. K/MP-54, through the Caijifornia Sea Grant Coliege (to V. V. F.). Our use of the RV 'Seward Johnson' was supported by the National Science Foundation, Chemistry and Oceanography Divisions, under grant CHE9008621 (to W.F.). Technical assistance was provided by Christopher Kauffman. We express our appreciation to Mr Colin Higgs, Ministry of Fisheries, Government of the Bahamas, for permission to perform research in their territorial waters. Contribution no. 233 to UNCW's Center for Marine Science Research.

\section{LITERATURE CITED}

Albizati K, Faulkner DJ (1985) Stevensine, a novel alkaloid of an unidentified marine sponge. J Org Chem 50:4163-4164

Albrizio S, Ciminiello P, Fattorusso E, Magno S (1995) Amphitoxin, a new high molecular weight antifeedant pyridinium salt from the Caribbean sponge Amphimedon compressa. J Nat Prod 58:647-652

Amade $P$, Chevolot $L$ (1982) Antimicrobial activities of marine sponges from French Polynesia and Brittany. Mar Biol 70: $223-228$

Amade P, Cherroin C, Baby C, Vacelet J (1987) Antimicrobial activities of marine sponges from the Mediterranean Sea. Mar Biol 94:271-275

Bergquist RP (1978) Sponges. Univ of California Press, Berkeley

Bergquist RP, Bedford JJ (1978) The incidence of antibacterial activity in marine Demospongiae: systematic and geographic considerations. Mar Biol 46:215-221

Burkholder PR, Rützler K (1969) Antimicrobial activity of some marine sponges. Nature 222:983-984

Chanas B, Pawlik JR, Lindel T, Fenical W (1996) Chemical defense of the Caribbean sponge Agelas clathrodes (Schmidt). J Exp Mar Biol Ecol 208:185-196

Dayton PK, Robilliard GA, Paine RT, Dayton LB (1974) Biological accommodation in the benthic community at McMurdo Sound, Antarctic. Ecol Monogr 44:105-128

Faulkner DJ (1998) Marine natural products. Nat Prod Rep 15 $113-158$

Herms DA, Mattson WJ (1992) The dilemma of plants: to grow or to defend? Q Rev Biol 67:283-335

Jenkins KM, Jensen PR, Fenical W (1998) Bioassay with marine organisms: Part II. Marine microbial chemical ecology. In: Haynes K, Millar JC (eds) Methods in chemi- cal ecology. Chapman and Hall, New York, p 1-32

Jensen PR, Harvell CD, Wirtz K, Fenical W (1996) Antimicrobial activity of extracts of Caribbean gorgonian corals Mar Biol 125:411-419

Kashman Y, Hirsh S, McConnell OJ, Ohtani I, Kusumi T, Kakisawa H (1989) Ptilomycalin A: a novel polycyclic guanidine alkaloid of marine origin. $J$ Am Chem Soc 111 $8925-8926$

Kelman D, Kushmaro A, Loya Y, Kashman Y, Benayahu Y (1998) Antimicrobial activity of a Red Sea soft coral, Parerythropodium fulvum fulvum: reproductive and developmental considerations. Mar Ecol Prog Ser 169:87-95

Koh EGL (1997) Do scleractinian corals engage in chemical warfare against microbes? J Chem Ecol 23:379-398

Mokashe S, Tulaskar A, Venkat K, Wagh A (1994) Antimicrobial properties of poriferan species from Indian waters. In: Thompson $M$, Nagabhushanam $R$, Sarojini $R$, Finger $M$ (eds) Recent development in biofouling control. Oxford and IBH, New Delhi, p 263-268

Nigrelli RF, Jakowska S, Calventi I (1959) Ectyonin, an antimicrobial agent from the sponge Microciona prolifera Verrill. Zoologica (NY) 44:173-175

Pawlik JR (1993) Marine invertebrate chemical defenses. Chem Rev 93:1911-1922

Pawlik JR, Chanas B, Toonen R, Fenical W (1995) Defenses of Caribbean sponges against predatory reef fish. I. Chemical deterrency. Mar Ecol Prog Ser 127:183-194

Quigley MM, Colwell RR (1968) Properties of bacteria isolated from deep-sea sediments. J Bacteriol 95:211-220

Reiswig HM (1973) Population dynamics of three Jamaician Demospongiae. Bull Mar Sci 23:191-226

Schmitt TM, Hay ME, Lindquist $N$ (1995) Constraints on chemically mediated coevolution: multiple functions for seaweed secondary metabolites. Ecology 76:107-123

Schmitz FJ, Gopichand RJ (1978) A novel dibromoacetylene acid from the marine sponge Xestospongia muta. Tetrahedron Lett 1978:3637-3640

Simpson TL (1968) The structure and function of sponge cells: new criteria for taxonomy of poecilosclerid sponges (Demospongia). Bull Peabody Mus Nat Hist 25:1-141

Stonard RJ, Andersen RJ (1980) Celenamides A and B, linear peptides alkaloids from the sponge Cliona celata. J Org Chem 45:3687-3691

Tachibana K, Scheuer JP, Tsukitani Y, Kiku-chi H, Engen VD, Clardy J, Gopichand Y, Schmitz JF (1981) Okadaic acid, a cytotoxic polyether from two marine sponges of the genus Halichondria. J Am Chem Soc 103:2469-2471

Targett NM, Schmahl GP (1984) Chemical ecology and distribution of sponges in the Salt River Canyon, St. Croix, U.S.V.I. NOAA Technical Memorandum OAR NURP-1, Rockville, MD, p 361-369

Thompson JE, Walker RP, Faulkner DJ (1985) Screening and bioassay for biologically-active substances from forty marine sponges species from San Diego California, U.S.A. Mar Biol 88:11-21

Uemura D (1991) Antitumor polyethers from marine animals. In: Scheuer JP (ed) Bioorganic marine chemistry, Vol 4 Springer-Verlag, New York, p 1-31

Wenner EL, Knott DM, Van Dolah RF, Burrell VG (1983) Invertebrate communities associated with hard bottom habitats in South Atlantic Bight. Estuar Coast Shelf Sci 17: $143-158$

Wilson DM, Puyana M, Fenical W, Pawlik JR (in press) Chemical defense of the Caribbean reef sponge Axinella corrugata against predatory fishes. J Chem Ecol

Zhuravleva T (1970) Porifera, Sphinctozoa, Archaeocyathiatheir connections. Symp Zool Soc Lond 25:41-59 